\title{
Appalachian English stereotypes: Language attitudes in Kentucky*
}

\author{
REID LUHMAN \\ Department of Sociology \\ Eastern Kentucky University
}

\section{A B S T R ACT}

Nonstandard language varieties typically become social markers of the social groups that use them. Through this connection, the varieties reflect commonly held stereotypes of those groups from the perspective of outsiders, as well as symbolize group membership for their speakers. This study employs the matched guise technique to compare attitudes toward Appalachian English and Standard American English held by speakers of both language varieties. Most studies of nonstandard language varieties have shown an acceptance by nonstandard speakers of dominant negative stereotypes of their groups. By varying content of speech samples evaluated, this study suggests that speakers of Appalachian English partially accept low status evaluations of their dialect, but reject other negative stereotypes of their speech community in terms of integrity and social attractiveness of its members. In particular, results suggest significantly higher evaluations of male speakers of Appalachian English that are shared by Standard English speakers. (Appalachian English, speech community, language variety, language markers, language stereotypes, dialects, social status)

Appalachian English is one of the surviving nonstandard regional dialects of English in the United States. It is associated with residents of the Appalachian mountain range, particularly with West Virginia and eastern Kentucky. Its current distinctiveness from Standard American English stems both from the isolated physical environment and from the industrial economic development of the area. The mountains have served until recently as an effective geographical barrier against physical mobility, and the coming of industrial economic development (which focused on resource extraction such as coal and timber) has proved detrimental to the economic mobility of its residents (Banks I980). Dialects thrive in such physical and social isolation.

Dialects are language varieties that are linguistically and generally also politically linked to a standardized language variety. The standard variety retains a degree of societal prestige through the official institutional support

(C) 1990 Cambridge University Press 0047-4045/90 \$5.00 +.00 
of government, written dictionaries and grammars, and historical tradition based on literary and/or religious use. As such, the standard variety is usually accepted as "proper" as compared to its dialects, which are considered as either quaint or simply incorrect offspring, depending on the social prestige of their speakers. Low status dialects come to be viewed interchangeably with their speakers as the dialects become associated with negative prestige. The economic exploitation of Appalachia has created and maintained a level of poverty in the area that has made Appalachian English not only a regional dialect but also a social dialect (i.e., a dialect related to social class) in the minds of most Americans (Fishman 1971).

Appalachian English differs from Standard American English in grammar, phonology, lexicon, and intonation (Wolfram \& Christian 1976). As with all dialects, it is not just an incorrect variation of the standard but is a language system in its own right with its own set of rules for correct speech. For example, a correct Appalachian English sentence, such as "I'm a-fixin' to do a right smart bit of work in the morning but they ain't no way I can git it done 'til pert 'near dinner time," suggests something of the range of variation possible. (Incidentally, "dinner" is the noon meal.) While this example comes close to a stereotype of Appalachian speech, the dialect is best described in terms of frequency of dialect elements used. It is possible, for example, to retain Appalachian phonology and parts of the lexicon while generally employing the grammar of Standard American English. Such an alteration would still mark the speaker as an Appalachian, but not as strongly as with the example given.

Speech is but one of the many markers of social position that we use to make guesses about others based on less than complete information. It carries more weight than most markers, however, since it is not so easily shed as a suit of clothes or a rusted and aging automobile. Although speech may be difficult to change, however, it can be accomplished, particularly over a number of generations. One of the persistent sociological questions that must be raised concerns the relative vitality of low status speech varieties in the face of widely held negative stereotypes. Language is far more than just a means of communication. It symbolizes our social experience in an intimate way and locates us within significant social groups from which we draw our identities. Ryan (1979) saw this solidarity function of speech as the primary reason for the survival of nonstandard (and low prestige) language varieties.

Nonstandard language varieties are usually associated with low social status groups and come to acquire the status evaluation of their speakers. Although perhaps less prone to stereotyping members of their own group, low status individuals are fully aware of their relative social position. Standard and nonstandard speakers alike stereotype standard speakers as superior in qualities such as intelligence, ambition, wealth, success, and education (see Arthur, Farrar, \& Bradford 1974; Bourhis \& Giles 1976; Brennan \& Bren- 
nan 198I; Carranza \& Ryan 1975; d'Anglejan \& Tucker 1973; Mazurkewich, Fister-Stoga, Mawle, Somers, \& Thibaudeau 1986; Ros i Garcia 1984). Whereas the first two qualities are more subjective than the remaining three, it is not surprising that such terms are applied quite consistently.

\section{RESEARCH DESIGN}

This study utilizes the matched guise technique developed by Lambert, Hodgson, Gardner, and Fillenbaum (1960) in their study of attitudes held by English- and French-speaking Canadians toward speakers of English, French, and a French-Canadian dialect. The technique is designed to eliminate extraneous variables so that the impact of language or dialect differences on social stereotypes can be measured directly. Participants are exposed to a variety of speech samples of different languages or dialects and are asked to make evaluative guesses about each speaker based only on his or her speech characteristics. The speakers who recorded the speech samples, however, are all bilingual (or bidialectal), so that each speaker records two samples (or guises), one in each language variety, which can later be matched for purposes of comparison. Since the same speaker made both recordings, any impact of voice tone on evaluations should affect both evaluations evenly; any differences in evaluations that remain should therefore be the result only of stereotypes the judge holds toward different languages or dialects. In such a research design, it is necessary to use a number of different bilingual or bidialectal speakers so that the judges encounter other speakers between each pair of samples from the same speaker and will believe they are evaluating different individuals each time. ${ }^{1}$

The dialects employed in this study are Standard American English (pronounced in the standardized form of "Network" English) and the eastern Kentucky subdialect of Appalachian English. Four bidialectal speakers, two men and two women in their early 2os, created the taped speech samples for the study. The speakers, who were all natives of Kentucky, were also actors who had learned the standardized accent of Network English for purposes of the stage. (The degree of standardness in the speech samples was evaluated by an independent group of 50 people to affirm that the speech samples were perceived as intended.) Rate and other aspects of speech were kept constant for each speaker across guises. The judges were all students at a university located at the edge of the bluegrass region of Kentucky where the mountains of eastern Kentucky begin. Most students at the university come from eastern Kentucky, central and northcentral Kentucky, and northern states. The sample of $\mathrm{I}_{7 \mathrm{I}}$ drawn from this population represented this spectrum.

The speech sample itself was a narrative monologue that lasted approximately $21 / 2$ minutes. It was written in conversational Standard American En- 
glish so as to be appropriate and meaningful in keeping with the narrator, who identified himself or herself as a graduating senior of the university. The Appalachian English version of the speech was left grammatically in the standard form but was clearly Kentucky accented in phonology and intonation. Although the speech sample could have been rewritten grammatically into Appalachian English, it was decided to keep the speech differences between the two samples at a minimal level. Grammatical variation much more sharply delineates speech communities as it is much more noticeable (Wolfram \& Fasold 1974). Although the purpose of matched guise research is to elicit stereotypes of speakers, the results of such research are more useful and interesting if those stereotypes appear when linguistic variation is minimal. In addition, Standard American English grammar is a common adaptation of eastern Kentucky students to university expectations; maintaining the same grammar in both sets of speech samples added realism to the speech.

Wolfram and Christian (1976) identified a range of phonological differences that distinguish Appalachian English from Standard American English. A number of those differences appeared in some or all of the Kentuckyaccented speech samples provided by the four speakers in this study, which presumably accounted for the perceptual differences of the judges. The primary phonological variations from Standard American English included:

1. Glide reduction. The elimination of the off glide on a word such as $m y$ produces a variation similar to mah. The speech sample intentionally included words such as my, like, alike, high, and right, some of them appearing more than once. All four speakers eliminated the off glide on these words.

2. Unstressed -ing. The speech sample included a large number of words ending in ing, ranging from common everyday words, such as nothing and having, to less common words, such as buildings and graduating. All four speakers replaced [ $\mathrm{\eta}$ ] with [n] in all cases, producing forms such as havin' and graduatin'. Although such variation is common to some extent in informal Standard English, both the degree of use and its use in words such as graduating mark the dialect as Appalachian English.

3. Consonant cluster simplification. The deletion of a final stop consonant following another consonant at the end of a word is a characteristic of Appalachian English; kept and except therefore become kep and excep (or sometimes cep; see point 4). Three of the four speakers dropped the final consonant on these two words in the speech sample; interestingly, it was a different three in each case, with Kim and Dwight exhibiting some variation here, each dropping the final consonant on one word but not the other. Hence, the variation appeared to some degree in each of the four speech samples.

4. Unstressed syllable deletion. The deletion of an unstressed syllable, such 
as ex in except, is a characteristic of Appalachian English and appeared on three of the four speech samples for that word.

5. Deletion of initial [ð]. This deletion appeared in the speech samples of Darren and Dwight for the word them, producing the phrase, "some of 'em" in place of "some of them." The latter form, of course, appeared on all four standard speech samples.

6. Substitution of [a] for [au]. This substitution makes homophones of hour and are. Hours appeared in the speech sample and received the substitution from all four speakers.

7. Substitution of [I] for [₹]. This substitution varied across speakers although it appeared at least once in each speech sample; all speakers turned forget into forgit, for example. Friend appeared several times in the speech sample and received this substitution regularly from Kim.

8. Rising pitch in declarative sentences. Two of the speakers, Dwight and Patricia, employed this variation in their Appalachian English speech samples. Dwight, for example, produced the utterance, "I found out that a lot of people came here with friends from home $>$ to share a dorm room $\lambda$. ." On the same sentence, Patricia included only the second rise in pitch. Such rises appeared three other times in Dwight's sample and two other times in Patricia's sample. Whereas such pitch rises are not limited to Appalachian English or even to nonstandard varieties in general, they are often markers of low status speech and/or low status speakers.

Research involving comparative evaluations of standard and nonstandard speech almost invariably results in significantly higher evaluations for the standard variety on the status dimension. In almost any country, standard speakers and nonstandard speakers view the former as more successful, intelligent, ambitious, wealthy, and educated. In this study, the only concrete information the judges learn about the speaker in the context of the speech sample is that he or she is a graduating senior from a university with good grades; this same information comes, of course, from both the standard speakers and the Kentucky-accented speakers. This part of the speech sample content was included in an attempt to bias the results away from the status stereotype so typically found. If the judges wished to rate Kentucky-accented speakers as low on the status dimension, they would have to do so against evidence to the contrary.

The content of the speech sample was also constructed to highlight the solidarity dimension. The content employed in this speech sample invited the judge to take sides. The speaker describes his or her experiences upon leaving home and coming to the university. In the course of this narrative, the speaker includes a tale of dormitory roommate incompatibility during the freshman year. The specifics of the incompatibility are left somewhat vague, but the speaker makes it clear that he or she and the roommate had very dif- 
ferent upbringings, led very different lifestyles, and had very different tastes. Not surprisingly, the speaker disliked the roommate. Such an observation can either be viewed as a justified grievance or as unjustified prejudice, depending on whether or not the judge identifies with the speaker. Some eastern Kentucky judges, for example, commented in open-ended parts of the study that the standard speakers sounded like snobs. This content encouragement to take sides brought out solidarity evaluations that other research often leaves below the surface.

At the opening of the research session, the judges were asked to fill out a questionnaire with primarily objective questions about themselves and their families, including some standard items pertaining to socioeconomic status coupled with information about where they were born and where they spent the majority of their childhood. The judges were also asked to indicate elements of their own language behavior that they would change if they could do so easily. While many of the judges selected some of the more neutral suggestions (such as "speak with more confidence in front of others"), very few of them indicated that they wished to alter either their grammar or pronunciation.

Following the initial questionnaire, the judges listened to and separately evaluated eight speech samples produced by the four bidialectal speakers. The samples were ordered so that the judges heard three other speakers before hearing the same speaker for the second time in a new dialect. Different groups of judges heard the speech samples in different orders. The speech sample evaluations consisted primarily of paired bipolar adjectives with seven spaces between each pair, allowing the judge to indicate which of the pair applied and to what degree; the middle space of the seven nullified the opposite adjectives so that the judges were not forced into making evaluations they felt unable to make. The status items included educated-uneducated, intelligent-unintelligent, wealthy-poor, successful-unsuccessful, and ambitious-carefree; the solidarity items included trustworthy-untrustworthy, good-bad, sympathetic-unsympathetic, friendly-unfriendly, honest-dishonest, and dependable-unreliable. For each speaker, the judges were asked to make guesses about the speaker as if they had overheard the speech that followed and knew nothing further about the speaker. The judges were also to indicate the degree to which the speaker sounded like themselves and members of their family. The judges would later be divided into two groups for each speaker, with those who indicated a mild or definite similarity between their own speech and that of the speaker separated from those who indicated a mild or definite difference.

One of the key variables used in this study is drawn from the last questionnaire item - the degree to which the judges identified a similarity of speech between themselves and each speaker. It has both important advantages and disadvantages for language research. On the minus side, individ- 
uals are not always the best judge of how they speak. Trudgill (1972) noted that men underestimated the standardness of their speech, whereas women overestimated that quality. Labov (I966) found that both men and women in his sample overestimated the similarity of their own speech to high status speech. People are either unable to hear how they actually speak or have strong preferences about how they wish to speak, which color their perceptions. However, the plus side of this variable for the present research stems from just this apparent shortcoming. Individuals' perceptions that their speech is similar to a speech community is in many ways a more important piece of information than the actual similarity of their speech to others in that community. In a study of the relationship of stereotypes to speech community membership, an individual's perception of his or her in-group is clearly connected to stereotypes held of the out-group.

\section{RESULTS}

The eight speech samples were judged by 50 evaluators on a 7-point scale that ranged from (I) nonstandard to (7) standard to affirm that the speech samples did indeed represent the intended guises. In addition, the judges were also asked to guess where each speaker might be from if they felt they could. Mean variation from the Kentucky-accented guise to the standard guise was significant in each case $(t<.0001)$. There was considerable agreement among the judges for three of the four speakers between the Kentucky-accented and standard guise means; respectively, speaker mean scores were Dwight (2.1 2 and 5.82), Patricia (3.18 and 5.62), Kim (r.98 and 5.38), and Darren (2.56 and 3.80). The one exception, Darren, included the relatively low standard guise mean of 3.80 , but this mean is misleading as the distribution was bimodal. Darren's standard guise was standard to the point of hypercorrection, which led some of the judges to place him geographically in Australia, Ireland, and England, thus making his speech nonstandard for those judges from an American perspective. Other judges placed him somewhere in the northern United States and rated his speech as extremely standard.

The distinctive phonology of Appalachian English was at one time a largely regional phenomenon, but social changes in the area have made the distribution of the phonology more complex. Geographical mobility out of eastern Kentucky coupled with the growing association of Appalachian English with low social status have produced a situation where not everyone in eastern Kentucky shares the phonology, while many outside do. To gain a clearer picture of this, the judges' identifications with the various speakers were compared to the regions in which they were born and spent their childhood. For this sample, these regions were grouped into four basic categories: (I) any northern state (which, for this sample, was predominantly Ohio), (2) urban areas in Kentucky, (3) rural areas in Kentucky except for eastern 


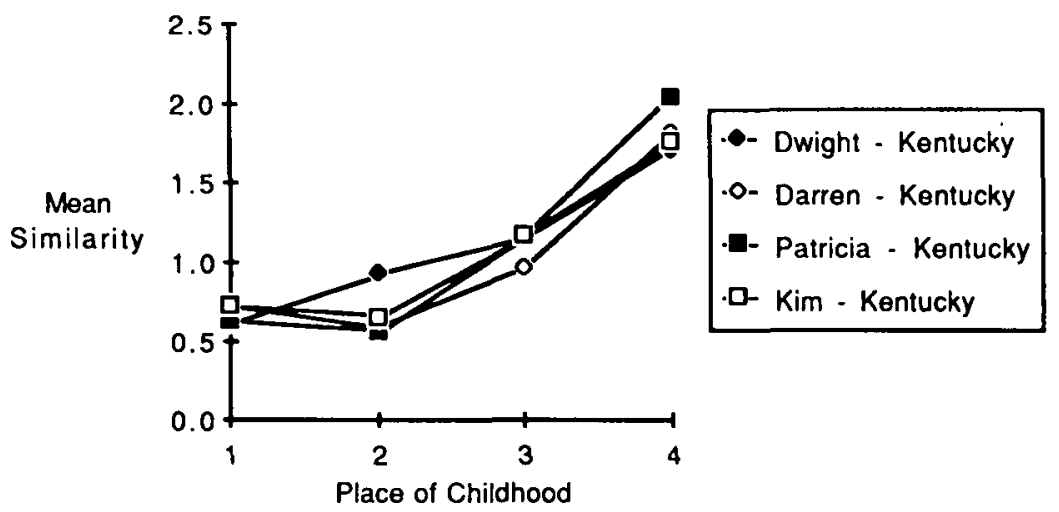
Key to Place of Childhood
1. Northern State $(n=32)$
2. Urban Area of Kentucky $(n=36)$
3. Nonurban Area of Central or Western Kentucky $(n=77)$
4. Nonurban Area of Eastern Kentucky $(n=21)$

FIGURE I: Mean evaluation scores of Kentucky dialect similarity by place of childhood.

Kentucky counties, and (4) eastern Kentucky. As there was little difference in results between place of birth and place of childhood, only the latter data will be presented. Figure I shows the mean scores of speaker identification with Kentucky-accented speech samples for each of the four regions. Scheffe's test indicates a significant difference $(p<.05)$ between eastern Kentucky judges and judges from the remaining three regions. As the graph indicates, however, rural non-eastern Kentucky judges also identify with Kentucky-accented speech. Of equal interest is the lack of identified similarity to Kentucky-accented speech by judges from urban areas of Kentucky; there is essentially no difference between their perception and that of northern judges. Since most of the urban Kentucky judges were also born in Kentucky, this finding suggests that in urban areas there is an increase in positive values attached to Standard English phonology. A study of actual speech samples would determine whether these values are reflected in speech or only in perceptions as measured here. In either case, urbanization has clearly had an impact on dialect change in Kentucky.

The paired adjectives of the scale items were selected to measure the twin dimensions of status and solidarity. To determine dimensionality, the scale items were factor analyzed with the principal components method followed by varimax orthogonal rotation. Two factors explained .615 of the variance with a drop in eigenvalue to .757 after the second factor had been extracted. It was felt that this justified the two-dimensional model of status and solidar-. 
TABLE I. Factor loadings of adjectives on solidarity and status factors

\begin{tabular}{lcc}
\hline & Factor 1 (Solidarity) & Factor 2 (Status) \\
\hline Trustworthy & .779 & .265 \\
Good & .767 & .258 \\
Sympathetic & .731 & -.047 \\
Friendly & .714 & -.068 \\
Honest & .697 & .226 \\
Dependable & .692 & .368 \\
Educated & .113 & .861 \\
Intelligent & .121 & .844 \\
Wealthy & -.061 & .786 \\
Successful & .313 & .783 \\
Ambitious & .260 & .593 \\
Eigenvalue & 4.666 & 2.099 \\
Variance (cumulative) & .424 & .615 \\
\hline \hline
\end{tabular}

TABLE 2. Mean factor scores on status and solidarity factors for Kentucky and standard speech evaluations for entire sample $(n=171)$

\begin{tabular}{llllllll}
\hline \hline & \multicolumn{3}{c}{ Status } & & \multicolumn{3}{c}{ Solidarity } \\
\cline { 2 - 3 } \cline { 7 - 8 } & Kentucky & Standard & \multirow{2}{*}{$F$} & & Kentucky & Standard & \multicolumn{1}{c}{$F$} \\
\hline Dwight & -.440 & .336 & $88.32^{* *}$ & .328 & -.022 & $13.49^{*}$ \\
Darren & -.709 & .585 & $209.34^{* *}$ & .297 & -.230 & $25.21^{* *}$ \\
Patricia & -.507 & .690 & $174.17^{* *}$ & -.273 & -.288 & .02 \\
Kim & -.613 & .658 & $197.84^{* *}$ & .102 & .087 & .02 \\
\hline \hline
\end{tabular}

*Significant at $p<.001$.

**Significant at $p<.0001$.

ity. Further justification comes from the factor loadings of the items following rotation (see Table $\mathrm{r}$ ), which show an evident simple structure.

The great advantage of factor analysis in this study lies in the simplification of the evaluation items into a form that matches the theoretical model. Once the factors were created, the next step was to calculate factor scores for each judge on each of the two factors for each speech sample. Utilizing this technique allows for the two-dimensional factor space plotting of speech sample evaluations from as few as one judge or as many as the entire sample. Figure 2 provides this most general picture of the data, showing the position of each of the eight speech samples on both factors as evaluated by the entire sample $(N=\mathbf{1 7} \mathrm{I})$. (Data and statistical one-way analysis of variance results concerning Figure 2 are presented in Table 2.) 


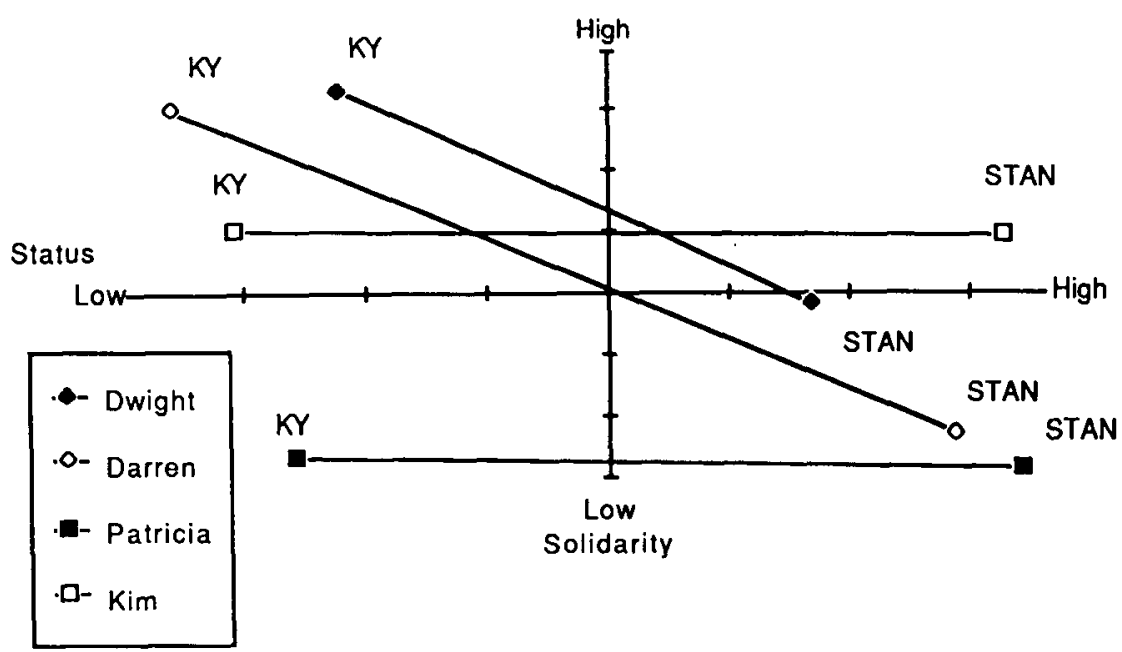

FIGURE 2: Status and solidarity factor score differences for Kentuckyaccented speech and Standard English.

Figure 2 contains two striking findings. First, the separation of the two dialects on the status dimension is evident as evaluated by the entire sample. Each speaker was rated significantly higher in his or her standard guise than in the Kentucky-accented guise in spite of the information about the educational status of the speaker provided in the speech sample. The evaluations depicted in Figure 2 suggest that even university graduates with traces of Appalachian English in their speech will automatically face stereotypes of low intelligence, lack of ambition and success, and a poor education (a university degree notwithstanding). It should be noted, of course, that the presence of Standard American English speech samples coupled with Appalachian English samples might have encouraged such a result, as judges might have felt compelled to look for contrasts; a comparison of two samples, each responding to only one dialect, would shed additional light on this matter.

The second striking finding depicted in Figure 2 was less expected and definitely calls for further research. While the two female speakers received no change in solidarity evaluations whatsoever across their two guises, the two male speakers each received statistically significant higher scores in solidarity while in their Kentucky-accented guises.

Since Figure 2 contains information for the entire research sample, an important question remains concerning levels of agreement about speech stereotypes among different subgroups within the sample. Using the measure of perceived similarity to the speaker already described, I divided the evaluations for each speech sample into those judges who tended to identify some 
TABLE 3. Mean factor scores for dialect identifying judges (+) and dialect nonidentifying judges (-) on status and solidarity factors

\begin{tabular}{|c|c|c|c|c|c|c|c|c|c|c|c|c|}
\hline & \multicolumn{6}{|c|}{ Status } & \multicolumn{6}{|c|}{ Solidarity } \\
\hline & \multicolumn{3}{|c|}{ Kentucky } & \multicolumn{3}{|c|}{ Standard } & \multicolumn{3}{|c|}{ Kentucky } & \multicolumn{3}{|c|}{ Standard } \\
\hline & + & - & $F$ & + & - & $F$ & + & - & $F$ & + & - & $F$ \\
\hline $\begin{array}{r}\text { Dwight } \\
n\end{array}$ & $\begin{array}{l}-.146 \\
(54)\end{array}$ & $\begin{array}{l}-.575 \\
(117)\end{array}$ & $10.71^{* *}$ & $\begin{array}{l}.515 \\
(88)\end{array}$ & $\begin{array}{l}.146 \\
(83)\end{array}$ & $12.61^{* *}$ & $\begin{array}{l}.382 \\
(54)\end{array}$ & $\begin{array}{l}.303 \\
(117)\end{array}$ & .29 & $\begin{array}{l}.183 \\
(88)\end{array}$ & $\begin{array}{l}-.238 \\
(83)\end{array}$ & $10.63^{* *}$ \\
\hline $\begin{array}{r}\text { Darren } \\
n\end{array}$ & $\begin{array}{l}-.345 \\
(47)\end{array}$ & $\begin{array}{l}-.847 \\
(124)\end{array}$ & $10.99^{* *}$ & $\begin{array}{l}.554 \\
(30)\end{array}$ & $\begin{array}{l}.591 \\
(141)\end{array}$ & .06 & $\begin{array}{l}.579 \\
(47)\end{array}$ & $\begin{array}{c}.190 \\
(124)\end{array}$ & $5.50^{*}$ & $\begin{array}{l}-.030 \\
(30)\end{array}$ & $\begin{array}{l}-.273 \\
(141)\end{array}$ & 1.58 \\
\hline $\begin{array}{r}\text { Patricia } \\
n\end{array}$ & $\begin{array}{l}-.303 \\
(54)\end{array}$ & $\begin{array}{l}-.601 \\
(117)\end{array}$ & $3.88^{*}$ & $\begin{array}{l}.588 \\
(79)\end{array}$ & $\begin{array}{l}.778 \\
(92)\end{array}$ & 2.85 & $\begin{array}{l}-.134 \\
(54)\end{array}$ & $\begin{array}{l}-.337 \\
(117)\end{array}$ & 1.49 & $\begin{array}{l}-.023 \\
(79)\end{array}$ & $\begin{array}{l}-.516 \\
(92)\end{array}$ & $9.51^{*}$ \\
\hline${ }_{n}^{K i m}$ & $\begin{array}{l}-.273 \\
(55)\end{array}$ & $\begin{array}{l}-.774 \\
(116)\end{array}$ & $9.73^{* *}$ & $\begin{array}{l}.715 \\
(90)\end{array}$ & $\begin{array}{l}.594 \\
(81)\end{array}$ & 1.66 & $\begin{array}{c}.248 \\
(55)\end{array}$ & $\begin{array}{l}.032 \\
(116)\end{array}$ & 1.60 & $\begin{array}{l}.286 \\
(90)\end{array}$ & $\begin{array}{l}-.134 \\
(81)\end{array}$ & $8.53^{*}$ \\
\hline
\end{tabular}

*Significant at $p<.05$.

**Significant at $p<.001$.

degree of speech similarity to the speaker and those who perceived more difference. Specifically, each judge was placed into a subgroup for each speaker; judges who described a speaker as somewhat or very similar to their own speech were placed in one subgroup, whereas those who described that speaker as somewhat or very dissimilar were placed in the other. A subgroup described as one that identifies with a given speaker is therefore composed of judges who described at least some degree of similarity between their own speech and that of the speaker. (It should be kept in mind that subgroups are not comparable from speaker to speaker.)

Table 3 contains a one-way analysis of variance of mean factor scores for these two subgroups for each of the eight guises on both the status and solidarity factors. With two exceptions, the subgroup that perceived some speech similarity with the speaker provided statistically significant higher evaluations on both status and solidarity factors. The major differences between subgroups concerned the status factor with Kentucky-accented speech and the solidarity factor with Standard English. With regard to status stereotypes of Kentucky-accented speech, those with a greater perceived similarity to that speech are less likely to accept the low status stereotype commonly associated with it. With regard to the solidarity factor differences between subgroups concerning Standard English guises, the noteworthy low levels of solidarity ratings from evaluators with a greater perceived dissimilarity between themselves and the standard speakers created significant differences between subgroups.

The numerical data presented in Table 3 are displayed graphically in Figure 3. Each speaker in each guise is located by two connected points on the 


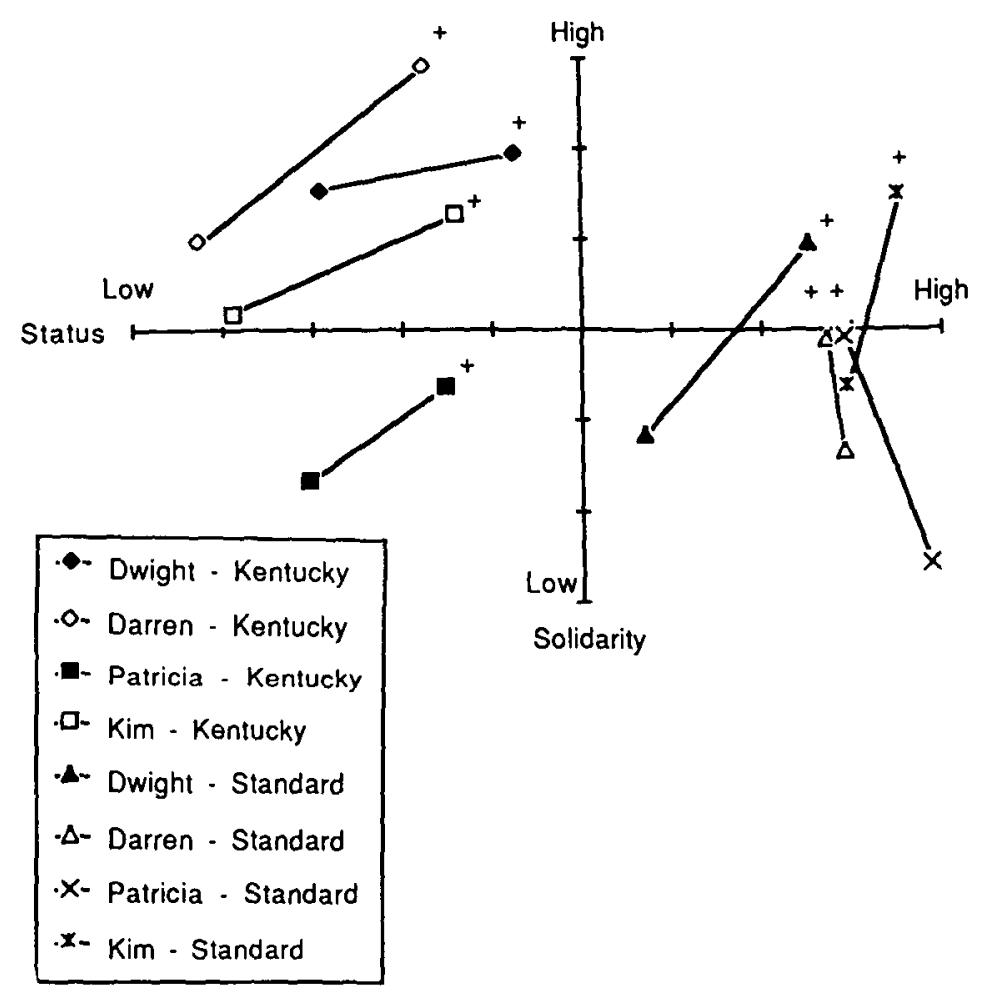

FIGURE 3: Status and solidarity factor scores for Kentucky and standard speakers.

chart, each point indicating two factor scores for a given subgroup. For each set of connected points, the point marked with a " + " indicates the factor scores of the subgroup that perceived a speech similarity to the speaker. As high status and high solidarity are found in the upper right-hand quadrant of the chart, the positive evaluations by these subgroups in most of the cases become obvious by the similar slopes of most lines toward that quadrant. Figure 3 highlights some findings that can easily be missed in Table 3. It was noted that subgroups that identified a similarity to Kentucky-accented speech were significantly less likely to accept the low status stereotype that nonidentifying subgroups accepted. However, Figure 3 shows clearly that all subgroups rate Kentucky-accented speakers toward the lower end of the status factor. Indeed, Figure 3 leaves no doubt about relative status differences in the evaluations of the two dialects; subgroups that don't identify with standard speakers rate those speakers noticeably higher on status than Kentuckyaccented speakers are rated by subgroups that identify with them. This is not 
surprising, however, as this finding is common to almost all research concerning nonstandard speech. It is in the nature of language standardization for there to be high social status connected with the standardized variety.

Figure 3 also suggests, in a general way, that Kentucky-accented English largely occupies the low status-high solidarity quadrant in stereotypes held by most members of this sample. By contrast, standard speakers are more respected than loved, occupying the high status-low solidarity quadrant for the most part. With regard to the two male speakers in their standard guises, evaluators who perceived a similarity to that speech did not evaluate the standard guises as highly on the solidarity factor as the nonidentifying evaluators (presumably, many of the same judges) rated the Kentucky guises. This suggests a general lack of enthusiasm on the solidarity dimension toward standard guises regardless of the perceived speech similarity between the evaluator and the speaker.

\section{DISCUSSION}

The relative ratings of the two language varieties on the status dimension are a common finding in language attitude research and were not unexpected here, in spite of efforts to minimize the degree of difference through making the speaker in each speech sample a university graduate. That addition to the content, however, may well have contributed to the differences between the two subgroups in degree of acceptance of the negative status stereotype. Several judges who spoke Kentucky-accented English asked later if they were supposed to have taken into account the university degrees and other content materials in the speech samples; they said they had. There is a strong possibility that judges less prone to stereotyping are also more likely to be attentive to such content materials. While those who identified their own speech as similar to Kentucky-accented English did not typically associate speakers of that language variety with great wealth and success (not equaling their evaluations of standard speakers, for example), they were certainly more open to the possibility than evaluators who did not identify with that speech. All four speakers in their Kentucky-accented guise elicited significant differences between subgroups on the status dimension.

The status dimension, as measured in most language attitude research, is a curious combination of objective and subjective evaluations. While items such as "education" and "wealth" should clearly be subject to objective agreement, other items such as "intelligence" and "ambition" should equally invite some subjective disagreement among evaluators. Is intelligence always measured by education? Does ambition always lead to wealth? Although research evaluators, including those in this study, always use these terms consistently (as measured by factor analysis), many of those same nonstandardspeaking judges believe that book learning does not equal common sense. A 
recognition that difference from higher status groups does not necessarily equal inferiority is tapped by the solidarity factor, but perhaps different methodological tools might more effectively measure a low status group member's respect for his or her own group. Respect for the skills of group members is a higher level of rebellion against dominant group values than the levels of likeability reflected in the solidarity factor. Although the methodology of this and similar research is perhaps not sensitive enough to detect it, such a level of respect may be an additional cause behind the statistically significant differences between subgroups on the status dimension.

With regard to ratings along the solidarity factor, one significant conclusion to be drawn from this research is largely methodological (although it certainly has importance for theoretical development as well). The content of the speech sample was constructed to highlight solidarity. In some similar matched guise research, there have been findings of low solidarity evaluations by nonstandard-speaking judges of nonstandard speakers. These findings may have been as much an artifact of research design as evidence of widespread self-hate among low status groups (see Carranza \& Ryan 1975; d'Anglejan \& Tucker 1973; Lambert 1967; Mazurkewich et al. 1986; Tucker \& Lambert 1969). Judges from eastern Kentucky in this study showed little interest in altering either their pronunciation or their grammar. Kentuckyaccented speech also clearly elicited high solidarity scores. The content of the speech sample employed in research could have played a major role in triggering attitudes of group solidarity and language loyalty that might otherwise have gone untapped.

If we break down the evaluators in this study into subgroups based on their perceived similarity of speech to each taped speaker, we see that many judges who did not identify similarities of their own speech with that of Kentucky-accented speakers also evaluated those speakers as equal to or higher than standard speakers on the solidarity factor (see Figure 3). Such ratings, termed "token appeasement" by Ryan, Hewstone, and Giles (1984), may in fact be reflective of positive associations with the nonstandard speech community, coupled with a realistic and meaningful speech sample that encouraged those positive associations to be expressed. Although many of those nonidentifying evaluators were from northern states, they were currently integrated within a Kentucky environment. A standard speaker uttering complaints can sound like a snob, even to a standard-speaking evaluator.

Although Kentucky-accented speakers generally were rated higher on the solidarity factor, a striking finding of this study is the differences in solidarity ratings of the two men across speech guises compared to the stability of the solidarity ratings of the two women across guises. Both male speakers dropped significantly in solidarity in their Standard English guises as eval- 
uated by all judges. Giles, Smith, Barry, Condor, and Thakerar (I980) studied the intersections of sex role and social class stereotypes in Great Britain using two of the six items used here on the solidarity scale ("friendly" and "sympathetic"). Other adjectives in their study encompassed the gist of the solidarity scale employed here. All of the items in their study were rated by evaluators as belonging in the working-class stereotype but independent of the sex-role stereotype (with the exception of "sympathetic," which was judged both working class and feminine). None of the adjectives appeared as both working class and masculine or as just masculine. In short, many of the solidarity items in the Giles et al. study seem connected with workingclass membership, which could account in this study for higher evaluations of low status nonstandard speakers by all evaluators. However, such findings do not explain differences in gender along the solidarity dimension. This finding is of particular interest in connection with other research concerning gender and loyalty to nonstandard speech.

Covert prestige was a term introduced by Trudgill (1972) to account for a curious and almost omnipresent finding from research in the sociology of language. Women in many Western countries and from many speech communities tend to be far more likely than men to acquire high status speech even when they occupy the same nonstandard speech community and the same social class (Kramarae 1982; Labov 1966; Smith 1979; Trudgill 1972, 1974, 1983). In addition, Trudgill (1972) noted gender differences in how men and women perceived their own speech; women tended to claim higher status speech behavior than they actually exhibited, whereas men tended to claim lower status speech behavior than they actually exhibited. This last finding in particular was puzzling as it suggested that men preferred to identify with a lower status speech community even if not warranted by their actual speech behavior. Explanations of these findings have been many and contradictory. Some of the researchers mentioned suggested the possibility of a "macho" component of nonstandard speech; others focused on the greater number of social connections among men in a speech community, which would increase their accommodation of speech to one another and perpetuate the nonstandard variety (cf. Giles \& Powesland 1975). Cameron and Coates (1985) argued that women have just as many ties to the community as men (although perhaps more difficult to measure) and that common measures of socioeconomic status less accurately reflect a woman's social status than a man's. The findings reported here, however, certainly give support to Trudgill's (1972) suggestion of the existence of covert prestige as it affects men. There is a definite similarity between the findings of this study and that of Gallois, Callen, and Johnstone (1984) in their Australian study of white and Aborigine language attitudes. Aborigine men were ranked high on solidarity by Aborigine and white Australian evaluators, whereas Aborigine 
women received low solidarity rankings from both groups of evaluators. Although it seems incredible to draw conclusions from such disparate locations as Australia, Appalachia, and Great Britain, Trudgill's connection between gender and loyalty to a nonstandard variety seems worth further attention. The high solidarity rankings given to nonstandard-speaking men in this and the Gallois et al. study would suggest a definite cause for such a connection, particularly when the high rankings come from standard speakers as well as from members of the nonstandard-speaking community. If your speech (or any other behavior, for that matter) generates positive stereotypes that are reflected in the behavior of others, there is certainly little incentive to change that speech. On the contrary, the basic processes of socialization should encourage a continuation of that behavior as well as the attachment of high ingroup values to it.

Covert prestige or any other kind of prestige cannot exist without high language variety vitality. However, the presence of that prestige does not explain the source of that vitality. According to the work of Giles, Bourhis, and Taylor (1977), the vitality of Appalachian English in its many forms appears to be primarily the result of regional demographics. Many Appalachian English speakers leave the area in search of economic opportunities elsewhere. Many also return, having faced discrimination based on the sum of the stereotypes described herein. But few move into the region who do not already have family ties within it. The nature of the natural resource extraction economy that dominates the area has kept the economic incentives for in-migration to a minimum. The high proportion of Appalachian English speakers thus maintained helps create the vitality necessary for dialect maintenance.

The fact that many Appalachians have temporarily lived elsewhere and faced negative stereotypes and prejudice toward their group creates an additional factor regarding in-group attitudes toward a nonstandard variety that can play a role in the vitality and maintenance of that variety. Knowledge that negative stereotypes about a group's speech exist elsewhere can serve to increase the level of in-group solidarity rather than decrease it. The vitality of Appalachian English is only hinted at by the findings of this study. The high solidarity ratings this variety received in light of the loaded nature of the speech sample about roommate incompatibility suggests some support of the theoretical work of Giles and Johnson (1986, 1987) regarding the role of outside threats - particularly in relation to matters of social solidarity in maintaining nonstandard language varieties. The roommate complaints were clearly not perceived in a social psychological vacuum but rather tapped into negative experiences and stereotypes typically encountered by speakers of Appalachian English. Such experiences serve to strengthen ethnic identification and group boundaries; in such social settings, linguistic differences become important boundary markers that require careful cultivation. 


\section{NOTES}

- The help of Howard Giles in reading earlier drafts of this article is much appreciated. This research was partially funded by an institutional research grant from Eastern Kentucky University. Invaluable research assistance was provided by Rex Barker, Dwight Craft, Kimberly First, Max Huss, Patricia Johns, Margaret Lane, and Darren McGee. Address correspondence to the author, Department of Sociology, 223 Keith, Eastern Kentucky University, Richmond, KY 40475, U.S.A.

I. This particular research design is traditional with matched guise research. An alternative design, in which two samples of evaluators drawn from the same population would respond separately to each dialect, would provide additional information to that reported here by minimizing the contrasts experienced by each evaluator.

\section{REFERENCES}

Arthur, B., Farrar, D., \& Bradford, G. (1974). Evaluation reactions of college students to dialect differences in the English of Mexican-Americans. Language and Speech 17:255-70.

Banks, Alan. (1980). The emergence of a capitalistic labor market in eastern Kentucky. $A p$ palachian Journal 7(3): 188-99.

Bourhis, Richard, \& Giles, Howard. (1976). The language of cooperation in Wales: A field study. Language Sciences 42:13-16.

Brennan, E., \& Brennan, J. (1981). Accent scaling and language attitudes: Reactions to Mexican American and English speech. Language and Speech 24:207-21.

Cameron, Deborah, \& Coates, Jennifer. (1985). Some problems in the sociolinguistic explanation of sex differences. Language and Communication 5(3):143-5I.

Carranza, M., \& Ryan, E. (1975). Evaluation reactions of bilingual Anglo and MexicanAmerican adolescents toward speakers of English and Spanish. International Journal of the Sociology of Language 6:83-104.

d'Anglejan, Alison, \& Tucker, G. Richard. (1973). Sociolinguistic correlates of speech style in Quebec. In R. Shuy \& R. Fasold (eds.), Language attitudes: Current trends and prospects. Washington, DC: Georgetown University Press. I-27.

Fishman, Joshua. (1971). The sociology of language: An interdisciplinary social science approach to language in society. In J. Fishman (ed.), Advances in the sociology of language. The Hague: Mouton. 217-404.

Gallois, Cynthia, Callen, Victor J., \& Johnstone, Michael. (1984). Personality judgements of Australian Aborigine and white speakers: Ethnicity, sex and context. Journal of Language and Social Psychology 3:39-57.

Giles, H., Bourhis, R., \& Taylor, D. M. (1977). Towards a theory of language in ethnic group relations. In H. Giles (ed.), Language, ethnicity and intergroup relations. London: Academic. 307-348.

Giles, H., \& Johnson, P. (1986). Perceived threat, ethnic commitment, and inter-ethnic language behavior. In Y. Kim (ed.), Interethnic communication: Recent research (Ioth Intercultural Communication Annual). Beverly Hills: Sage. 9I-116.

(1987). Ethnolinguistic identity theory: A social psychological approach to language maintenance. International Journal of the Sociology of Language 68:69-99.

Giles, H., \& Powesland, P. F. (1975). Speech style and social evaluation. New York: Academic.

Giles, H., Smith, Phillip M., Ford, Barry, Condor, Susan, \& Thakerar, Jitendra N. (1980). Speech style and the fluctuating salience of sex. Language Sciences 2:260-82.

Kramarae, Cheris. (1982). Gender: How she speaks. In E. Ryan \& H. Giles (eds.), Attitudes towards language variation: Social and applied contexts. London: Edward Arnold. 84-98.

Labov, William. (1966). The social stratification of English in New York City. Washington, DC: Center for Applied Linguistics.

Lambert, Wallace. (1967). A social psychology of bilingualism. Journal of Social Issues 23(2):91-109. 
Lambert, Wallace, Hodgson, R., Gardner, R., \& Fillenbaum, S. (1960). Evaluative reactions to spoken language. Journal of Abnormal and Social Psychology 60:44-51.

Mazurkewich, Irene, Fister-Stoga, F., Mawle, D., Somers, M., \& Thibaudeau, S. (1986). A new look at language attitudes in Montreal. Genetic, Social and General Psychology Monographs I I 2(2):20I-I 7.

Ros i Garcia, Maria. (1984). Speech attitudes to speakers of language varieties in a bilingual situation. International Journal of the Sociology of Language 47:73-90.

Ryan, E. (1979). Why do low-prestige language varieties persist? In H. Giles \& R. N. St. Clair (eds.), Language and social psychology. Oxford: Blackwell. 145-I 57 .

Ryan, E., Hewstone, M., \& Giles, H. (1984). Language and intergroup attitudes. In J. Eiser (ed.), Attitudinal judgement. New York: Springer. 135-58.

Smith, Phillip M. (1979). Sex markers in speech. In K. Scherer \& H. Giles (eds.), Social markers in speech. Cambridge: Cambridge University Press. 109-146.

Trudgill, Peter. (1972). Sex, covert prestige and linguistic change in the urban British English of Norwich. Language in Society 1:179-95.

(1974). The social differentiation of English in Norwich. Cambridge: Cambridge University Press.

(1983). Sociolinguistics: An introduction to language and society (revised ed.). Harmondsworth: Penguin.

Tucker, G., \& Lambert, W. (1969). White and Negro listener's reactions to various AmericanEnglish dialects. Social Forces $47: 463-68$.

Wolfram, W., \& Christian, D. (1976). Appalachian speech. Arlington, VA: Center for Applied Linguistics.

Wolfram, W., \& Fasold, R. W. (1974). The study of social dialects in American English. Englewood Cliffs, NJ: Prentice-Hall. 